\title{
Planos diretores e participação política: políticas públicas de planejamento entre 0 empresariamento e 0 estatuto da cidade ${ }^{1}$
}

\author{
Jefferson O. Goulart \\ Universidade Estadual Paulista / Faculdade de Arquitetura, Artes e Comunicação \\ Bauru / SP - Brasil \\ Eliana Tadeu Terci \\ Universidade de São Paulo / Escola Superior de Agricultura Luiz de Queiroz \\ Piracicaba / SP - Brasil \\ Estevam Vanale Otero \\ Universidade Metodista de Piracicaba / Faculdade de Engenharia, Arquitetura e Urbanismo \\ Santa Bárbara d'Oeste / SP - Brasil
}

\begin{abstract}
Tomando como referencial teórico-metodológico a revisão da literatura temática interdisciplinar e o estudo comparado de três cidades médias do interior paulista - Piracicaba, Bauru e Rio Claro -, o texto analisa a efetividade de planos diretores participativos em um contexto paradoxal no qual emergem, de um lado, a exigência legal de fazer planos com base na função social da propriedade e em processos participativos e, de outro, forte pressão para que os municípios atraíssem investimentos e replicassem o modelo do empresariamento urbano em suas políticas públicas. Em um cenário de democratização do país e de um novo arranjo institucional para o planejamento urbano - no qual se destacam o capítulo da Política Urbana da Constituição de 1988 e a Lei Federal no 10.257/2001 (Estatuto da Cidade) —, o exame empírico contemporâneo evidencia a baixa eficácia dos planos diretores e a variação da experimentação participativa em sua efetiva capacidade de democratizar decisões, destacando-se como variável decisiva a conduta dos governos de turno quanto à participação.
\end{abstract}

Palavras-chave: políticas públicas de planejamento; participação política; planos diretores; empresariamento; estatuto da cidade.

DOI: http://dx.doi.org/10.1590/0034-7612147853

(c) (1)

Artigo recebido em 30 mar. 2015 e aceito em 4 abr. 2016.

${ }^{1}$ Este artigo apresenta resultados da pesquisa "Processos contemporâneos de desenvolvimento urbano em cidades médias: Estatuto da Cidade, expansão imobiliária, engrenagem econômica e dinâmica decisória político-institucional (2001-2011)", financiada pela Fundação de Amparo à Pesquisa do Estado de São Paulo (Processo Fapesp 2011/140823), cuja versão preliminar foi apresentada na Seção Temática "Estado, Planejamento e Política" do XVI Encontro da Associação Nacional de Pós-Graduação e Pesquisa em Planejamento Urbano e Regional (Enanpur), realizado em Belo Horizonte, Brasil, maio de 2015. 
Planes de ordenación urbana y participación política: políticas públicas de planificación entre el empresariamiento y el estatuto de la ciudad

Adoptando como referencial teórico-metodológico la revisión de la literatura temática interdisciplinaria y el análisis comparado de tres ciudades intermedias en el estado de São Paulo — Piracicaba, Bauru y Rio Claro -, el artículo investiga la efectividad de los Planes de Ordenación Urbana Participativos en un contexto paradójico: de un lado, la disposición legal de ejecución de Planes basados en la función social de propiedad y en procesos participativos y, de otro, fuerte presión para que los municipios buscasen atraer inversiones y reprodujesen el modelo del empresarialismo urbano. En un escenario de democratización del país y de un nuevo arreglo institucional para el planeamiento urbano - destacándose la Constitución de 1988 y la Ley Federal 10.257/2001 (Estatuto de la Ciudad) —, el examen empírico evidencia la baja eficacia de los Planes y la diversidad de experiencias participativas en su efectiva capacidad de democratizar la toma de decisiones, destacando como variable fundamental la importancia que cada gobierno ha dado a la participación.

Palabras clave: políticas públicas de planificación urbana; participación política; planes de ordenación urbana; empresarialismo; estatuto de la ciudad.

Master plans and political participation: public planning policies to establish a link between entrepreneurship and city ordinances

Using the review of interdisciplinary thematic literature on the subject and a comparative study of three medium-sized cities in the interior of São Paulo State, Piracicaba, Bauru and Rio Claro as its theoretical and methodological framework, this paper analyzes the effectiveness of Participatory Master Plans within a paradoxical context. You have, on the one hand, the legal requirement to design plans based on the social function of property and using participatory processes and, on the other, you have strong pressure for municipalities to attract investment and reproduce the urban entrepreneurship model in their public policies. In a scenario where the country is undergoing a democratization process and where you have a new institutional arrangement for urban planning, as in, for example, the chapter on Urban Policy in the Constitution of 1988 and Federal Law № 10.257/2001 (City Ordinances), a contemporary empirical examination clearly shows the limited efficiency of Master Plans. It is also clear that the variation of participatory experimentation in their effective capacity to democratize decisions is low, highlighting the fact that the conduct of current governments is decisive with regard to such participation.

KEYWords: public planning policies; political participation; master plans; entrepreneurship; city ordinances.

As facções da classe dominante brasileira com interesses mais ligados à produção do espaço urbano estão na seguinte encruzilhada: por um lado, têm cada vez menos condições de fazer planos que revelem suas reais propostas para nossas cidades, e por outro não têm condições de fazer planos que atendam às necessidades da maioria de suas populações.

Flávio Villaça 


\section{Introdução}

Este texto apresenta resultados parciais de pesquisa sobre processos contemporâneos de desenvolvimento urbano, cujo objetivo consiste em avaliar o alcance democratizante e a eficácia de Planos Diretores Participativos em três cidades médias do interior do estado de São Paulo, a saber, Piracicaba, Bauru e Rio Claro. Essa análise leva em conta os novos parâmetros institucionais impostos pela Constituição Federal e pela Lei no 10.257/2001 (Estatuto da Cidade), os quais reorientaram normativamente os processos de elaboração e implantação de políticas públicas de planejamento urbano no Brasil. ${ }^{2}$ A metodologia empregada - mediante revisão da literatura temática interdisciplinar, inventário e sistematização dos dados das fontes locais e análise empírica da implantação dos Planos — possibilitou formular critérios analíticos comparativos para identificar aspectos comuns ou particulares de cada cidade que tenham influído nos resultados produzidos.

Explicações a priori foram recusadas porque ignoram a especificidade do objeto de pesquisa, vale dizer, seu caráter apriorístico antecipa respostas inadequadas à originalidade dos problemas teóricos e empíricos dos processos de urbanização de cidades médias.

Ainda no plano teórico-metodológico, foram buscadas respostas abrangentes mediante o exame das relações de interdependência entre as três variáveis básicas da pesquisa, a saber, as dimensões físico-territorial, socioeconômica e político-institucional. A amplitude do escopo investigativo teve como contrapartida a formulação de hipóteses explicativas mais abrangentes. A noção de processo implica um funcionamento sistêmico, com conjuntos de dimensões e relações que comportam contextos, atores e parâmetros institucionais que estabelecem entre si múltiplos níveis de determinação e causalidade que produzem molduras e resultados cuja incidência não se limita isoladamente a cada um deles. ${ }^{3}$

Análises sobre o desenvolvimento urbano que se circunscrevem à dimensão espacial, embora possam esclarecer muito sobre os interesses fundiários e a dinâmica imobiliária, não capturam necessariamente os interesses econômicos que as determinam, desconhecem as correspondentes disputas sociais e tampouco se articulam às dinâmicas decisórias que envolvem diferentes atores e imposições institucionais (normas, leis, governos, legislativos etc.). Entendimento abrangente sobre o desenvolvimento urbano precisa necessariamente abarcar todas as dimensões mencionadas para apreender os elementos decisivos aos padrões e resultados

\footnotetext{
${ }^{2} \mathrm{O}$ estudo implicou amplo levantamento sobre a evolução urbana dos municípios selecionados, com base em diversas fontes secundárias de diferentes instituições (IBGE, Seade, prefeituras), além de depoimentos de protagonistas desses processos (governantes, legisladores, empreendedores do setor imobiliário, dirigentes de entidades civis etc.), os quais estão sistematizados no Relatório Final da referida pesquisa. Os dados e análises aqui apresentados sintetizam a abordagem da dimensão político-institucional da investigação.

${ }^{3}$ No plano teórico, os resultados contribuem para o aprofundamento do debate sobre a conformação das cidades brasileiras, reflexão interdisciplinar que envolve a produção de diferentes áreas do conhecimento — especialmente do urbanismo, da economia, da ciência política, da sociologia urbana, da gestão pública e da geografia humana — na perspectiva de elevar o entendimento sobre as realidades urbanas das cidades médias.
} 
da evolução urbana que têm se consagrado. Ademais, estudos comparados oferecem respostas mais consistentes às questões precedentes sobre as particularidades e as similaridades que marcam o desenvolvimento urbano de cidades médias.

O recorte cronológico adotado (o decênio 2001-11) não foi casual. A última década foi marcada pela implantação do Estatuto da Cidade, paradigma cuja originalidade reside em significativa ampliação de prerrogativas dos municípios, na exigência de mecanismos participativos nas decisões públicas e na subordinação da lógica urbana às funções sociais da cidade e da propriedade mediante diversos instrumentos de regulação urbanística. A experimentação fática, contudo, exige balanço que transcende seu valor normativo original, percurso aqui desenvolvido com o propósito de avaliar criticamente a efetividade do marco institucional e dos Planos Diretores Participativos.

A análise foi organizada com o seguinte roteiro: na próxima seção (2), são enunciadas as características fundamentais que distinguem as políticas públicas e o marco institucional da política urbana; na seção seguinte (3), de abordagem analítica e conceitual, são sumariados o contexto, a trajetória e os termos em que emerge a temática da participação, até o período contemporâneo em que se destaca seu processo de institucionalização; na parte que se segue (4) são abordados os elementos do novo marco regulatório da política urbana brasileira, com destaque para a análise sobre o papel dos municípios e a difusão das novas concepções mercadológicas e competitivas sintetizadas pelo empresariamento urbano e pelo planejamento estratégico das cidades; na seção subsequente (5), tratamos da experiência empírica dos processos decisórios contemporâneos e dos Planos Diretores Participativos das cidades selecionadas, adotando o enfoque metodológico proposto por Avritzer (2008) mediante análise de três variáveis: (i) os termos com que a participação se organiza, (ii) em que medida e com qual alcance o Estado absorve a participação e (iii) qual o peso do marco institucional no tipo de decisão produzida; na seção derradeira de conclusões, algumas hipóteses de síntese.

\section{Políticas públicas e marco institucional}

A literatura especializada define o campo das políticas públicas como a disciplina investida do desafio de interpretar o Estado em sua dimensão reguladora efetiva, ou seja, para além de qualquer abstração, políticas públicas traduzem plataformas de instituições e atores políticos e respondem às demandas societárias. Nesse sentido, são instituídos códigos normativos e tomadas decisões por autoridades governamentais que definem regras que tanto podem alterar como manter o status quo, de modo que "a política pública permite distinguir entre o que o governo pretende fazer e o que, de fato, faz" (Souza, 2007:80). Dessa perspectiva, tratamos das políticas públicas de planejamento urbano no Brasil sob uma moldura institucional em processo de democratização.

Ao contrário da abordagem de alguns estudiosos das transições para a democracia na América Latina - que reduziram suas análises aos regimes políticos, à remoção de ditaduras e sua substituição por sistemas democráticos no âmbito estritamente institucional (Linz e 
Stepan, 1996) —, no Brasil esse processo é bem mais complexo, multidimensional, porque envolve múltiplas facetas, entre as quais: a) a própria democratização da sociedade e de suas instituições (Stepan, 1988); b) a institucionalização das experiências participativas, à medida que, "ao longo da segunda metade dos anos 1990 e na década seguinte, a participação passou a ser, cada vez mais, participação-em-espaços-participativos" (Lavalle e Vera, 2011:117); c) a consolidação de um "Estado de direito" e de direitos civis, pois “um componente 'politicista', ou baseado unicamente no regime, é necessário, mas insuficiente para uma definição adequada de democracia" (O’Donnell, 1998:39); d) uma ruptura do modelo desenvolvimentista de Estado, com profundas consequências socioeconômicas e uma crise de hegemonia (Sallum Jr., 1996). Em síntese, as transformações do modelo de Estado e a democratização compreendem dimensões complementares que não se circunscrevem à mudança de regime político.

Na agenda do planejamento urbano, a primeira inovação foi o arranjo federativo da Constituição de 1988 (Goulart, 2013), que reconheceu o município como ente federado autônomo e soberano, responsável pela gestão de políticas públicas de desenvolvimento urbano. A segunda novidade foi o inédito marco regulatório de política urbana, sintetizado pelos enunciados constitucionais (artigos 182 e 183) e posterior regulamentação pelo Estatuto da Cidade (Lei Federal ํㅜ 10.257/2001), cuja originalidade reside na exigência de mecanismos decisórios participativos e na subordinação da dinâmica urbana à função social da propriedade. A terceira inovação institucional foi a criação do Ministério das Cidades, em 2003, como agência de articulação das políticas de Estado de desenvolvimento urbano.

A Constituição também impôs a obrigatoriedade do Plano Diretor para municípios com população superior a 20 mil habitantes e o definiu como "instrumento básico da política de desenvolvimento e de expansão urbana”. Ademais, o Estatuto da Cidade ratificou o princípio da "gestão democrática por meio da participação da população e de associações representativas dos vários segmentos da comunidade na formulação, execução e acompanhamento de planos, programas e projetos de desenvolvimento urbano" (art. $2^{\circ}$ ).

Tais mudanças pretenderam alterar a forma de produzir decisões sobre as políticas urbanas, substituindo o antigo modelo tecnocrático e autoritário que se confunde com a história do planejamento urbano no país (Villaça, 2004), além de introduzir um vasto elenco de instrumentos urbanísticos capazes de oferecer terra urbanizada, conter a especulação imobiliária e assegurar a função social da propriedade urbana (Estatuto da Cidade, 2002).

Reflexo dessas imposições institucionais e da ação do Ministério das Cidades, em 2009, "dos 1.644 municípios com mais de vinte mil habitantes, 1.433 declararam ter Plano Diretor, o que corresponde a 87\% do total" (Santos Jr. e Montandon, 2011:29). Dados quantitativos exigem análises qualitativas sobre a efetividade participativa e dos instrumentos urbanísticos, esforço aqui empreendido comparativamente em três cidades médias paulistas.

Como não há um levantamento qualitativo amplo e sistemático sobre a efetividade dos Planos Diretores no período contemporâneo, tanto na literatura do planejamento urbano quanto no campo da administração pública, parte dessa lacuna pode ser superada com pesquisas comparadas que examinem suas condições político-institucionais e as respectivas dinâmicas de tomada de decisões. Tais formatos decisórios não dependem unicamente dos 
correspondentes arranjos institucionais, ou seja, o contexto histórico e outras variáveis são determinantes para mensurar resultados que também "dependem das atitudes da elite e da população que formam o contexto subjetivo que dá sentido e vida às instituições e constitui a substância da convivência civil em regimes democráticos" (Almeida e Carneiro, 2003:125).

Dessa perspectiva interdisciplinar de enquadramento do objeto, se dá a inserção das políticas públicas de planejamento urbano no campo da "investigação em administração pública, [a qual] não se restringe aos estudos da gestão de organizações governamentais e/ou das ações do setor público", de sorte que o debate sobre o espaço público se materialize em "temas de interesse estruturados em torno do objeto Estado: papéis, estratégias, estruturas, atores, processos, relações e poder, e das suas transformações a partir de crises e reformas" (Fadul et al., 2014:1336). ${ }^{4}$

Ademais, é fundamental incorporar a noção de accountability à eficácia das políticas públicas porque esse conceito remete ao imperativo de que os governos prestem contas de seus atos: "an effective government is one that achieves results that respond to the needs of its citizens and is accountable to them. It manages by and for results and makes decisions based on credible data and robust evidence" (Sandiso, 2015:124). Ou seja, a gestão pública precisa tanto de "dados críveis" e "provas sólidas" para produzir resultados satisfatórios quanto de responsividade para coordenar, regular e implantar políticas públicas.

\section{A institucionalização da participação}

Espaço público para a participação societária constitui tema recorrente da teoria democrática e, particularmente no Brasil, foi uma das características sociopolíticas mais vigorosas da transição para a democracia (Avritzer, 2012), razão suficiente para não reduzir esse processo à sua dimensão político-institucional.

Novos atores entraram em cena: um sindicalismo de novo tipo que não aceitava a tutela estatal herdada do populismo e movimentos sociais urbanos que se organizaram em torno de temas e políticas públicas específicas (saúde, moradia, educação, gênero, creche, direitos humanos, reforma urbana etc.). Em comum, todos se situavam fora da sociedade política, e precisamente por serem outsiders mantiveram relações bastante diferentes com o Estado. Em resumo, "a sociedade civil brasileira ressurgiu durante o processo chamado de 'liberalização' que começou durante meados dos anos setenta" (Avritzer, 2012:387).

As plataformas desses movimentos foram progressivamente dirigidas para o Estado porque envolviam correspondentes políticas públicas. O processo constituinte foi o desaguadouro das mais variadas demandas da sociedade civil. Isso ocorreu não só porque, no tipo de transição que tivemos e em momentos críticos (como nas passagens de regimes políticos), o polo

\footnotetext{
${ }^{4}$ Para uma visão política panorâmica da história recente sobre o debate da reforma do Estado no Brasil, ver especialmente o depoimento de Luiz Carlos Bresser-Pereira (Queiroz, 2014).
} 
dinâmico da democracia tende a ser a sociedade civil (Araujo, 2009), mas também porque a própria democracia era limitada, bastando lembrar a eleição indireta para presidente em 1985 e o controverso formato congressual da Constituinte em 1986. Inscrever direitos na Constituição e formular parâmetros institucionais de políticas públicas foram as formas encontradas pela ação coletiva para obter ou ampliar ganhos e assegurar espaço na partilha de bens materiais e imateriais.

Assim anunciava-se a institucionalização da participação, especialmente por meio da inclusão de atores sociais nos processos de elaboração e implantação de políticas públicas. Tais inovações imprimiram uma crítica implícita ao modelo liberal-pluralista de democracia, para o qual, numa perspectiva minimalista, o sistema democrático se restringe à construção de minorias legítimas para governar.

O exame da trajetória da democracia brasileira confirma os limites do governo representativo e a criatividade das inovações democráticas; no entanto, a explicação desses fenômenos nem sempre é apropriada. Há um equívoco conceitual quanto à participação: qualquer que seja a inovação (conselhos gestores de políticas públicas, Orçamento Participativo, Planos Diretores Participativos etc.), todas, sem exceção, transcorrem à base da representação, isto é, não podem ser tipificadas como "democracia direta" precisamente porque supõem intermediações entre decisores e as decisões tomadas.

A expressão "participação" é usada genericamente para designar formatos decisórios extraparlamentares que transcendem o sufrágio. Tais mecanismos não só têm um caráter complementar como não substituem a representação, tanto dos partidos políticos que detêm seu monopólio quanto dos governantes que detêm legitimidade para governar. Mais: as decisões produzidas implicam diversas mediações, de modo que entre estas e os decisores são necessárias muitas interposições institucionais (normas, esferas intermediárias, transferência de prerrogativas para representantes, códigos jurídicos etc.).

Nesses termos, ocorreu um deslocamento interpretativo correspondente que não só atentou para os movimentos de seu objeto como incorporou à análise as mudanças mais gerais do governo representativo, e assim "da defesa de um modelo participativo de democracia transitou-se para o estudo de inovações institucionais bem-sucedidas e da sua capacidade de introduzir correções dentro da dinâmica mais geral do governo representativo" (Lavalle e Vera, 2011:118). A participação de que se trata envolve representação (eleição, delegação de poder, limitação decisória etc.). Logo, é imperativo evitar abordagens maniqueístas que opõem bem e mal: no caso, o bem representado por uma sociedade civil benfazeja por natureza e universalista em suas demandas e o mal, por um Estado intransponível e inexoravelmente clientelista, tecnocrático e elitizado.

Em síntese, "pode-se afirmar que o modelo conselhista de gestão de políticas e programas no Brasil não só se consolidou nos últimos nove anos, como se ampliou" (Buvinich, 2014:72). Esse movimento de institucionalização da participação colocou novos problemas para as relações entre Estado e sociedade civil, pois esta ingressou em uma esfera decisória partilhada que não se resume à posição polar (entre Estado e sociedade civil). A participação não só manteve os vínculos com seu lugar de origem (a sociedade civil) como conservou seus 
registros simbólicos e identitários (democratização, autonomia, inclusão, autodeterminação); no entanto, ao assumir posições nos espaços participativos, também incorporou responsabilidades na formulação e implantação de políticas públicas. No campo da administração pública e em perspectiva normativa, "a construção de espaços públicos pode alcançar patamares qualificados de debates e decisões quando se estabelece a institucionalização de instrumentos e mecanismos a serem utilizados em seus processos de gestão", percurso que permite "potencializar os fluxos participativos, decisórios e de controle social em face das ações que são executadas" (Kleba, Comerlatto e Frozza, 2015:1076).

Há, inegavelmente, um forte componente democratizante nesse processo que remete à ideia de controle social do Estado por parte da sociedade civil, qual seja, alargar os procedimentos democráticos na gestão pública, o que se consumou (embora não exclusivamente) por meio de conselhos gestores de políticas públicas. Além da subjacente crítica à representação, que limita a poliarquia à eleição de minorias legítimas, há claramente uma expectativa de ampliação do universo de decisores; no entanto, entre o que se preconiza normativamente e o que de fato ocorre há uma larga distância. Nesses termos, "os Conselhos, ao se institucionalizarem, convertem-se em aparelhos do Estado, com as mesmas vicissitudes das demais instituições do poder político", donde se pode inferir da análise mais geral dessas experiências que, "assim como o controle social, lato sensu, nasce do questionamento à efetividade da democracia representativa, também os instrumentos criados para esse controle precisam da vigilância da sociedade para bem funcionar" (Gurgel e Justen, 2013:375).

\section{Política urbana e empresariamento das cidades}

Os municípios ganharam musculatura político-institucional e financeira na Constituição de 1988 (Oliveira, 1995; Leme, 1992), não obstante a União ter se mantido forte (Arretche, 2009), e assim a política urbana passou a ser competência dos governos locais: reza a Constituição que a política de desenvolvimento urbano é "executada pelo poder público municipal" (art. 182).

Parâmetros institucionais, porém, não são suficientes para a efetivação de políticas públicas, pois há outras variáveis a considerar, incluindo as mediações político-institucionais e os obstáculos conjunturais e estruturais. Um desses fatores obstaculizantes se refere ao contexto socioeconômico do país, aos efeitos da crise do modelo desenvolvimentista e às transformações das sociedades capitalistas desse período, o que fez emergir a demanda por governos locais empreendedores. Houve, assim, um deslocamento importante na atribuição desses atores, que deixaram de ser somente responsáveis pela provisão de infraestrutura, bens e serviços urbanos (gerenciadores) para também se tornarem empreendedores econômicos que promovessem diversificação e modernização de negócios em seus territórios, em geral com sobreposição de atividades terciárias e industriais. Governos locais deveriam assumir atribuições antes conferidas aos níveis superiores - segurança, relações internacionais, empreendedorismo econômico etc. - para atrair novos investimentos em um cenário de escassez de recursos e de acirramento da competição entre cidades (Castells e Borja, 1996). 
Manifestações dessa tendência não devem ser automaticamente replicadas de sua origem (nos países centrais do capitalismo) às nações do "capitalismo tardio". Não obstante, no Brasil essa tendência se revelou expressiva, incluindo cidades médias que se beneficiaram do processo de interiorização do desenvolvimento e da desconcentração industrial no passado recente (sobretudo na década de 1970), e que depois sofreram os impactos da recessão da "década perdida" e da abertura dos mercados nos anos de 1990 sob o impulso neoliberal e se viram na contingência de empreender e atrair novos investimentos.

Muitos municípios reproduziram essa postura empreendedora, criando estruturas administrativas orientadas para o desenvolvimento econômico. Em Piracicaba foi criada a Secretaria Municipal de Indústria e Comércio, em 1997, depois renomeada como Secretaria Municipal de Desenvolvimento Econômico, em cujas atribuições se destacam a "elaboração de instrumentos promotores da indústria, comércio e de serviços no município" e "um canal entre a Iniciativa Privada e o Governo Municipal, proporcionando maior integração entre o Poder Público e as Indústrias, Comércios e Empresas Prestadoras de Serviços". " Em Bauru, foi instituída a Secretaria Municipal do Desenvolvimento Econômico, em 1999, "com o objetivo de buscar investidores para a cidade, estimular parcerias, dar apoio à iniciativa privada e produtiva da cidade, atuando na indústria, comércio, prestação de serviços e turismo". ${ }^{6}$ Em Rio Claro não foi diferente: criada em 1994, à Secretaria de Desenvolvimento Econômico cabe "planejar, estudar, desenvolver e executar políticas para o desenvolvimento, ciência, tecnologia e inovação", além de "incentivar a implantação de programas de qualidade e produtividade na indústria e serviços". ${ }^{7}$

Órgãos dessa natureza têm baixa dotação orçamentária e suas ações tendem a ser mais de articulação institucional e representação com seu público-alvo (empreendedores privados), de modo que ações administrativas desse tipo não encerram a atuação dos governos locais, mas se evidencia claramente a tendência ao empresariamento das cidades, ou seja, uma forma sofisticada de "reificação (coisificação) da cidade" que se caracteriza principalmente

pela parceria público-privada tendo como objetivo político e econômico imediato (se bem que, de forma nenhuma exclusivo) muito mais o investimento e o desenvolvimento econômico através de empreendimentos pontuais e especulativos que a melhoria das condições em um âmbito específico. [Harvey, 1996:53]

\footnotetext{
${ }^{5}$ Informações disponíveis em: < http://transparencia.inovare.net/piracicaba/legislacao/leis > e em <www.semdec. piracicaba.sp.gov.br/goto/store/textos.aspx?SID =8c7836278e1316240c94d36a32b4e6b5\&id=15> . Acesso em: 27 jan. 2014. A criação e a renomeação do órgão foram patrocinadas por prefeitos do PSDB, respectivamente, Humberto de Campos (1997) e Barjas Negri (2007).

${ }^{6}$ Disponível em: <www.bauru.sp.gov.br/secretarias/sec_desenvolvimento/asecretaria.aspx>. Acesso em: 27 jan. 2014. A promulgação da lei que criou o órgão ocorreu no governo do prefeito Antonio Izzo Filho (PPB).

${ }^{7}$ Disponível em: <www.rioclaro.sp.gov.br/secretarias/deconomico.php>. Acesso em: 28 jan. 2014. O órgão foi criado na primeira gestão do prefeito Nevoeiro Jr. (PFL).
} 
Essa perspectiva reduz a cidade à sua dimensão mercantil (produto a ser negociado) e se orienta pela competição. No caso brasileiro, esse fenômeno se tornou mais visível, de um lado, pelo colapso do padrão desenvolvimentista e posterior liberalização econômica (que gerou desindustrialização) e pela crise fiscal do Estado, traduzindo-se na redução do financiamento à infraestrutura urbana e no arrefecimento da capacidade estatal de coordenar o desenvolvimento regional e urbano; e, de outro, pela desordenada ação dos governos locais visando a atrair investimentos escassos, a qual se expressou na guerra fiscal e nas atraentes e (por vezes) desmedidas ofertas de incentivos a empreendedores privados. As raízes desse fenômeno são identificáveis na década de 1970, por ocasião do movimento de desconcentração industrial (Cano, 1988), quando municípios do interior paulista criaram distritos industriais oferecendo toda sorte de infraestrutura (terra urbanizada, serviços de terraplenagem e pavimentação, saneamento etc.), além de perda de receita por renúncia fiscal (IPTU, sobretudo).

Com a crise econômica da "década perdida" e o crescimento medíocre dos anos de 1990, não foram poucos os casos em que as cidades tentaram alavancar processos locais e regionais de desenvolvimento da perspectiva do empresariamento como alternativa de atração de investimentos. Há casos emblemáticos de adoção do "planejamento estratégico das cidades" no Brasil — como do Rio de Janeiro (Arantes, Vainer e Maricato, 2000) —, mas o fenômeno se manifestou alhures e nas cidades aqui analisadas, ainda que mais tardiamente, como em Piracicaba ("Projeto Piracicaba 2010") e em Bauru ("Bauru + 10"), ambos liderados por segmentos privados com algum nível de aquiescência do poder público.

Em Piracicaba, sob a liderança de uma multinacional, a Caterpillar do Brasil, desencadeou-se amplo processo de articulação que envolveu técnicos e especialistas, dirigentes e gestores empresariais, acadêmicos e gestores públicos em torno de um "projeto de cidade". Justificado como iniciativa "suprapartidária da sociedade civil", o processo alcançou alto grau de institucionalização que culminou com sua transformação em Organização da Sociedade Civil de Interesse Público (Oscip) que, inclusive, triangulou captação e aplicação de recursos federais para projetos de requalificação urbana, caso do "Projeto Beira-Rio". Em Bauru, o "Bauru + 10" teve origem em uma articulação de acadêmicos e de representantes do governo municipal (Santos, 2003); no entanto, só ganhou expressão com a adesão de representantes empresariais articulados em torno do Centro das Indústrias do Estado de São Paulo (ciesp).

Nessas duas situações, a ideia do planejamento estratégico foi lastreada retoricamente nas exigências de "desenvolvimento sustentável" da "Agenda 21" e não parece acidental que tivessem usado insígnias similares, respectivamente "realizando o futuro" e "construindo o futuro", expressões que designam efetividade - algo que o planejamento urbano convencional teria perdido a capacidade de realizar. O "planejamento estratégico" seria, assim, um "planejamento de resultados" em um contexto de fragilidade econômica e de crise de credibilidade da matriz e das ferramentas tradicionais do planejamento urbano moderno.

Embora essa concepção tenha sofrido mediações, a ideia fundamental de que gestores públicos devam assumir o papel de empreendedores se tornou potente e foi amplamente propagada. Não por acaso, tal percepção se disseminou nos tempos em que o ideário neoliberal dominou o debate sobre o desenvolvimento (inclusive urbano). A adesão ao empresariamento 
das cidades não requer a adoção formal do "Planejamento Estratégico das Cidades" e de suas técnicas e ferramentas metodológicas - embora essa combinação aconteça em alguns casos —, mas sua disseminação foi uma reação para que os municípios assumissem uma postura proativa na dinamização econômica, cujas implicações são múltiplas: urbanísticas na medida em que (re)orientam e impactam as decisões relativas à produção do espaço urbano, e políticas porque modelam e limitam os correspondentes processos decisórios de desenvolvimento urbano.

Em Rio Claro não há registro de adoção explícita ou formal de "planejamento estratégico", mas o município também aderiu ao empresariamento urbano ao implantar um programa agressivo de atração de empresas: o Programa de Desenvolvimento de Rio Claro (Proderc), iniciativa criada em 1993 e reformulada pela Lei no 2.788 , de 6 de dezembro de $1995 .^{8}$ Mediante esse programa e, sobretudo, de renúncia fiscal, o poder público local pretendeu estimular a instalação e a ampliação de empresas. As contrapartidas das empresas foram mensuradas basicamente através de metas de empregabilidade, gozando de isenção (total ou parcial) de IPTU, ISSQN, ITBI, além de várias outras vantagens e benesses. ${ }^{9}$

\section{Os Planos Diretores Participativos}

No contexto de institucionalização da participação, de disseminação do empresariamento e de implantação do novo marco regulatório da Política Urbana, agora serão analisados empiricamente os processos de elaboração e implantação dos Planos Diretores de Piracicaba, Bauru e Rio Claro, todos transcorridos após a vigência do Estatuto da Cidade. ${ }^{10}$

No cenário de consolidação democrática do país, é possível identificar três modalidades de instituições participativas "através das quais os cidadãos ou associações da sociedade podem participar do processo de tomada de decisão política" (Avritzer, 2008:45): a primeira (e mais efetiva em termos de democratização) seria a do Orçamento Participativo (OP), um formato de "baixo para cima" assim definido porque permitiria a livre entrada de qualquer cidadão nos correspondentes processos decisórios; a segunda (de efetividade intermediária), mais difundida e institucionalizada, seria a "partilha de poder", materializada pelos conselhos de políticas públicas, na qual "atores estatais e da sociedade civil participam simultaneamente" das decisões; o terceiro formato seria o de "ratificação pública", exemplificado pelos Planos Diretores, no qual "os atores da sociedade civil não participam do processo decisório, mas são chamados a referendá-lo publicamente” (Avritzer, 2008:46).

\footnotetext{
${ }^{8}$ O programa foi implantado pelo Executivo municipal durante a gestão do prefeito Nevoeiro Jr. (PFL) e mantido em todas as gestões seguintes, vigorando até hoje.

${ }^{9}$ Disponível em: <www.canalrioclaro.com.br/noticia/6122/noticia/6123/noticia/6123/.html>. Acesso em: 3 fev. 2015. ${ }^{10}$ As fontes dos dados apresentados referem-se à legislação urbanística das cidades selecionadas, aos registros institucionais disponíveis nas respectivas prefeituras e às informações coletadas pela pesquisa de campo, tanto por meio de entrevistas quanto de documentação oficial.
} 
Os Planos Diretores seriam o formato "menos dependente da vontade do governo" porque o marco regulatório da política urbana impõe a obrigatoriedade de processos participativos, conforme o Estatuto da Cidade. São várias as ocorrências em que a exigência da participação é explicitada no EC: como diretriz geral no artigo $2^{\circ}$, inciso II; nas audiências do Poder Público municipal e da população interessada, conforme artigo 2º, inciso XIII; na garantia da participação da sociedade civil no controle dos instrumentos de políticas urbanas, conforme o artigo 4을 §3; ; na instituição de instrumentos de gestão democrática da cidade, ver artigo 43, incisos I, II, III e IV; na forma de gestão orçamentária participativa, prevista no artigo 44; e na garantia de controle direto das atividades dos organismos gestores das regiões metropolitanas e aglomerações urbanas, conforme artigo 45; debates, audiências e consultas públicas no artigo 43, inciso II; nas conferências municipais sobre temas urbanos, conforme artigo 43, inciso III; na gestão orçamentária participativa, ver artigo 44; no uso do referendo popular e do plebiscito, conforme previsão constitucional e da Lei Federal no 9.709/1998 (Estatuto da Cidade, 2002:229-231). Contudo, na medida em que essas imposições são relativamente genéricas, sua aplicação depende basicamente das formas aplicadas e das escolhas dos governos locais quanto aos termos e ao alcance dessa participação. Isto posto, a orientação político-ideológica e o conteúdo programático do governo de turno serão determinantes para a inclusão e extensão de formatos participativos. Portanto, ao contrário do que sustenta Avritzer (2008), a dependência do sistema político (também) é alta no caso dos Planos Diretores Participativos.

Em Piracicaba, a elaboração do Plano Diretor Participativo teve início em 2003, no governo do prefeito José Machado (PT). No total, foram contabilizadas 10 audiências públicas (gerais e temáticas), duas conferências (para apresentação de eixos e princípios da nova legislação) e dois congressos, nos quais foram discutidos e votados os conteúdos do novo Plano. Em termos de conteúdo, foi incorporado praticamente todo o ferramental do Estatuto da Cidade: Macrozoneamento; Parcelamento, Edificação e Utilização Compulsórios; IPTU Progressivo no Tempo; Transferência do Direito de Construir; Outorga Onerosa do Direito de Construir; Direito de Preempção; Consórcio Imobiliário; Estudo de Impacto de Vizinhança (EIV); Zonas Especiais de Interesse Social (Zeis) etc.

O projeto do Plano Diretor só foi concluído após o II Congresso da Cidade, sendo encaminhado ao Legislativo municipal em dezembro de 2004. No mesmo ano, porém, foi eleito um novo prefeito, Barjas Negri (PSDB). Ante essa mudança governamental, o projeto original foi retirado para reavaliação e uma nova versão foi encaminhada ao Legislativo em dezembro de 2005, sendo transformada em lei em outubro de 2006 (Lei Complementar no 186). Depois disso, foram feitas outras cinco complementações no Plano Diretor, cujas alterações flexibilizaram regras mais restritivas de uso e ocupação do solo. ${ }^{11}$

Neste caso, a adesão à orientação do empresariamento das cidades é evidente: mesmo não havendo supressão de instrumentos urbanísticos do Estatuto da Cidade incorporados ao

\footnotetext{
${ }^{11}$ Para uma apreciação integral do Plano Diretor e das leis complementares que se seguiram, ver o site do Ipplap. Disponível em: <http://ipplap.com.br/site/plano-diretor/>. Acesso em: 10 jan. 2014.
} 
Plano Diretor, a prioridade do novo governo local foi basicamente a de coordenar um ciclo de expansão econômica que se beneficiou das condições macroeconômicas favoráveis daquele momento. Para tanto, procedeu a sucessivas ampliações do perímetro urbano, incluindo a instalação do Parque Automotivo de Piracicaba no qual se estabeleceram uma grande montadora de automóveis e outras indústrias de autopeças, sinalizando nitidamente "que as políticas econômica e fiscal sobrepuseram-se e afetaram a política urbana" (Goulart, Terci e Otero, 2013:192-193). No cômputo final, de todos os instrumentos contidos na lei do Plano Diretor, somente as Zeis e o EIV foram objeto de regulamentação.

Em Bauru, o Plano Diretor Participativo foi elaborado na gestão do prefeito José Gualberto (Tuga) Angerami (PDT), de 2005 a 2008. ${ }^{12}$ O congresso que concluiu o processo mobilizou diferentes setores sociais e coroou um intenso esforço de articulação societária, tendo sido "eleitos 130 delegados urbanos e rurais, sendo que 43 deles eram representantes das entidades de classe, de sindicatos e de instituições de pesquisa" (Rigitano, 2008), os quais "participaram de cursos de capacitação para aprofundamento dos conhecimentos sobre os instrumentos do Estatuto da Cidade e suas aplicações" (López, 2013:31).

Somando-se todas as etapas do processo, a metodologia participativa contabilizou 114 reuniões com presença de um público estimado de quase 5 mil pessoas, desde participações individuais até representação de órgãos governamentais de diferentes níveis federativos, entidades de classe, sindicatos patronais e de trabalhadores, organizações comunitárias etc. Até a formulação do projeto de lei e realização do congresso, não houve contestações substantivas no debate público. Já na tramitação legislativa do projeto foram explicitadas divergências que foram processadas e negociadas no âmbito da comissão temporária constituída pelo Legislativo. Duas manifestações na forma de propostas de diretrizes e emendas merecem registro. A primeira do Centro das Indústrias do Estado de São Paulo (Ciesp) e a segunda do Sindicato da Indústria da Construção Civil (SindusCon-SP).

Coerente com os interesses que organiza, o Ciesp propôs ações para dinamizar o setor industrial local mediante priorização de investimentos em logística, traduzindo-se na criação de um Centro de Logística Integrado. Ademais, sugeriu a criação de minidistritos industriais e enfatizou a oportunidade de políticas de "atração de investimentos no setor industrial e melhor aproveitamento da zona rural em benefício da zona urbana” (López, 2013:35). Já o SindusCon-SP escolheu o vereador João Parreira de Miranda (PSDB), ligado ao setor imobiliário da cidade, como interlocutor para se manifestar. Para tanto, argumentava que "as novas normas sejam benéficas à cidade, sem engessar o desenvolvimento do setor", posição traduzida na objeção "ao Coeficiente de Aproveitamento Único e à limitação do perímetro urbano - tidos como empecilhos ao pleno desenvolvimento do setor, e demonstraram apreensão quanto à adoção do instrumento de Outorga Onerosa” (López, 2013:37). A entidade enviou

\footnotetext{
${ }^{12}$ Tuga foi eleito pelo PDT em 2004, mas se desfiliou do partido antes de cumprir metade do mandato, permanecendo sem filiação partidária até o fim de sua gestão. Antes, já havia sido prefeito de 1983 a 1988, destacando-se pela orientação de esquerda e pelo perfil progressista.
} 
documento ao Legislativo em junho de 2007, no qual indicava as mudanças mais importantes. Sintomaticamente, "no mesmo dia e para o mesmo destinatário, o Grupo Pró-Bauru, ${ }^{13}$ formado por entidades de diversas categorias empresariais atuantes no município, formalizou seu apoio às modificações sugeridas pelo SindusCon-SP” (López, 2013:38).

O projeto do Executivo foi aprovado e ganhou forma legal na Lei no 5.631, de 22 de agosto de 2008, que instituiu o Plano Diretor Participativo de Bauru, legislação orientada pelo Estatuto da Cidade (Macrozoneamento, Zonas Especiais de Interesse Social, Outorga Onerosa, IPTU Progressivo, Direito de Preempção, Estudo de Impacto de Vizinhança, Transferência do Direito de Construir). Contudo, apenas as Zeis foram regulamentadas pela Lei no $5.766 / 2009$, o que se explica pela necessidade de o município dispor de instrumentos institucionais para implantar o Programa Minha Casa Minha Vida (Carvalho, 2013).

O instrumento privilegiado de participação na política urbana - tanto na fiscalização do poder público como na formulação e implantação de políticas públicas - era o Conselho do Município, previsto no artigo 247 da lei do PDP, só implantado no final de 2013.

Em Rio Claro, o processo pioneiro de elaboração e aprovação do novo Plano Diretor transcorreu durante a gestão do prefeito Dermeval da Fonseca Nevoeiro Jr. (PFL), desde outubro de 2005 e culminado na Lei no 3.806, de 28 de dezembro de 2007. Embora reproduza genericamente alguns enunciados do Estatuto da Cidade, a versão final da lei municipal não inclui instrumentos consagrados como o Macrozoneamento e a Outorga Onerosa (e, consequentemente, sem inclusão de coeficientes de aproveitamento básico e máximo).${ }^{14}$ No período seguinte não ocorreu qualquer regulamentação dos instrumentos incluídos na lei e, além disso, a legislação complementar (Leis de Zoneamento, Parcelamento do Solo etc.) também não foi feita, tornando na prática o Plano Diretor inócuo.

Diante de um Plano Diretor sem efetividade e com baixo nível de debate público, esse percurso mudou a partir de 2008, quando foi eleito o novo prefeito, Palmínio (Du) Altimari Filho (PMDB). Na 3ํㅡㄹ Conferência da Cidade, em 2010, os participantes aprovaram a proposta de revisão do Plano, antes mesmo do prazo previsto. Em termos de conteúdo, a proposta de revisão incluiu os princípios do Estatuto da Cidade, merecendo destaque a "promoção da função social da propriedade urbana" (art. 3o, inciso III) e a "adoção de soluções urbanísticas que ampliem as condições de segurança e evite a fragmentação, espraiamento e a compartimentação do tecido urbano" (art. 3o, inciso XXIV) (Ribeirão, 2012:21). Nesse sentido, há avanços em relação à legislação de 2007.

Apesar das audiências públicas e mesmo da formulação de uma nova minuta de projeto de lei, este sequer foi protocolado no Legislativo municipal porque mudou a orientação política do governo em relação à legislação urbanística: ao invés da aprovação de um novo

\footnotetext{
${ }^{13}$ Embora fossem articulações sociais diferentes, o "Grupo Pró-Bauru” (basicamente empresarial) também é influenciado pelo ideário do planejamento estratégico que distinguiu o "Bauru +10 " (integrado por acadêmicos, empresários e outros).

${ }^{14}$ A íntegra do Plano Diretor pode ser acessada no site da Prefeitura do Município de Rio Claro. Disponível em: <www.rioclaro.sp.gov.br/pd/arquivos/Lein3806-2007.pdf>. Acesso em: 7 fev. 2014.
} 
Plano Diretor — revisão da lei aprovada em 2007 —, optou-se por investir na aprovação de leis complementares específicas e segmentadas, casos das Leis Complementares nos 81 e 82, ambas de 25 de setembro de 2013, que tratam, respectivamente, do parcelamento do solo urbano e rural no município e do zoneamento urbano, uso e ocupação do solo.

O arrefecimento do ímpeto político do governo obviamente enfraqueceu o debate sobre o Plano Diretor, inflexão explicada pela escolha de ordenar as políticas urbanas com base em regulações específicas (zoneamento, parcelamento etc.) sem, contudo, arcar com os custos políticos de uma legislação abrangente e mais restritiva, caso do Plano Diretor inspirado no Estatuto da Cidade. Em síntese, Rio Claro tem em vigência um Plano Diretor inefetivo porque os instrumentos disponíveis não foram regulamentados.

O exame empírico confirma que a experimentação participativa varia em sua capacidade de democratizar decisões. Essa variação compreende a capacidade organizativa da sociedade, a disposição dos governos de incorporar esses experimentos participativos e ainda inclui o grau de exigência participativa imposto pelo marco jurídico (Avrtizer, 2008). Embora todas essas variáveis pesem, as evidências indicam que as dimensões decisivas foram, respectivamente, a conduta do governo de turno quanto à participação e a (limitada) capacidade organizativa da sociedade civil.

A literatura internacional contemporânea confirma essa prevalência da ação governamental: "it is clear, therefore, that one way of making governance operative is the way in which local politicians exercise their power, whilst the distinction between active and proactive roles seems secondary" (Brugué e Vallès, 2005:222). Portanto, a forma como o poder é exercido pelos governos locais e seus representantes é determinante para os resultados produzidos em termos de participação política, ainda que se possa contestar a incidência e o peso qualitativo de papéis ativos e proativos.

Em todos os casos analisados, a participação transcorreu por meio de representação: escolha de delegados, transferência decisória (independente de seu alcance), participação em foros institucionais e conselhos. Em resposta aos dilemas implícitos - quem decide e com quais procedimentos - , os governos decidiram efetivamente sobre as políticas de regulação urbana, e os procedimentos decisórios incluíram algum grau de participação societária: maior no caso de Bauru durante a elaboração do Plano Diretor; intermediária em Piracicaba; e inferior em Rio Claro, ainda que a revisão antecipada tenha origem na Conferência da Cidade, em 2010. Em suma, a participação teve contornos de ratificação da posição governamental.

Analogamente, o Legislativo revelou posição homologatória quanto à legislação urbanística, constatação explicada tanto pelo arranjo decisório que assegura primazia ao Executivo (poder de agenda, monopólio de iniciativa legislativa em matérias como legislação orçamentária e urbanística) quanto pelo despreparo para tratar de matérias complexas que exigem conhecimento técnico, familiaridade institucional etc. O quadro 1, ao final desta seção, sintetiza as três experiências comparativamente.

A experiência participativa de Bauru é a mais expressiva não só pelos critérios quantitativos, mas porque foi socialmente mais abrangente e constante, incluindo as circunstâncias de pactuação com o Legislativo, o que só foi possível pela efetividade da ação política gover- 
namental. Não obstante, em nenhum momento o governo prescindiu de exercer o controle tanto sobre os procedimentos participativos quanto do conteúdo da legislação, ensejando uma experiência de caráter inequivocamente homologatório. Somente nesse caso, porém, propostas do segmento empresarial foram explicitadas como tal. Paradoxalmente - no município onde a participação foi mais expressiva durante a elaboração do Plano Diretor —, depois da mudança governamental (do PDT para o PMDB), a participação que se seguiu foi lenta e de baixa institucionalização, bastando constatar a demora na instalação do Conselho do Município, o que ocorreu somente no final de 2013, cinco anos após a aprovação do Plano.

A experiência participativa de Piracicaba também foi mais expressiva na primeira fase de elaboração do Plano, arrefecendo significativamente no período posterior à mudança governamental (do PT para o PSDB). Já na fase de implantação da nova legislação, as alterações conduzidas pelo governo abandonaram os preceitos do Estatuto da Cidade e a gestão foi conduzida sob a lógica do empresariamento e da expansão imobiliária. A participação limitou-se à liturgia formal e burocratizou-se, sem que a representação societária manifestasse objeções à nova orientação do desenvolvimento urbano. Num caso e no outro, contudo, as decisões mais relevantes sempre foram monopolizadas pelo Executivo municipal, que, quando precisou, aprovou-as no Legislativo com folgadas maiorias.

Todas as mudanças praticadas pelo governo na legislação urbanística - ampliação do perímetro urbano, concessões e benefícios a empresas privadas, alterações nas normas de uso e ocupação do solo, regulamentação de alguns instrumentos do Plano Diretor etc. — não só não tiveram participação societária em seus contornos como também o Legislativo as aprovou docilmente. Não há registro de manifestações contrárias ou críticas de vereadores e de conselhos a qualquer dessas modificações.

Importa pouco a composição formal desses conselhos - e no caso do Conselho da Cidade, foro apropriado para esses debates, essa proporção é paritária: de seus 32 membros, 16 representam a sociedade civil —, pois as instituições efetivamente decisórias são outras. A tomada de decisões relevantes eventualmente tramita pelos conselhos, e quando muito eles são chamados e pressionados a chancelar as posições do governo. Mesmo que os conselhos se reúnam periodicamente, que haja determinada institucionalização em seu funcionamento e que, em alguns casos (como o do Conselho da Cidade), tenham caráter "deliberativo", essa prerrogativa é limitada ao âmbito de suas atribuições.

Concorreram para esse cenário duas razões complementares: fraqueza da sociedade civil e potência do Estado. A fragilidade da organização societária quanto ao debate sobre o planejamento urbano pode ser exemplificada pela inação dos Conselhos de Habitação e de Mobilidade e pelo "sumiço" de movimentos sociais que em décadas passadas protagonizaram a cena política, tais como a Associação dos Favelados de Piracicaba ${ }^{15}$ e o movimento de mutuários. Desmobilização, a propósito, que se generalizou e não é exclusiva dessa cidade (Maricato, 2011).

${ }^{15}$ A esse respeito, ver Siqueira (1993). 
Em Rio Claro, o Plano Diretor teve menos participação em sua elaboração. A mudança de governo (do PFL para o PMDB) possibilitou a reabertura dos debates sobre o desenvolvimento urbano mediante a revisão do Plano Diretor, inclusive com papel importante desempenhado pelo Conselho de Desenvolvimento Urbano (CDU). Todavia, também nesse caso a prova definitiva de que o governo manteve controle sobre o processo foi a paralisia legislativa na tramitação da proposta de revisão do Plano Diretor, que ainda não foi votada por opção política do Executivo.

Como a atração de investimentos depende de incentivos diversos e de abrandamento de normas urbanísticas restritivas, a aplicação dos instrumentos dos Planos Diretores poderia obstruir ou inibir a recuperação econômica e assim comprometer o dinamismo de segmentos como o industrial, da construção civil, o terciário etc. Não por acaso, embora os Planos das três cidades analisadas tivessem incorporado formalmente muitos dos instrumentos urbanísticos regulatórios, sua regulamentação foi pífia (Zeis e EIV em Piracicaba e apenas Zeis em Bauru). Fato é que uma cidade regulada urbanisticamente nos termos do Estatuto da Cidade não interessa a diversos segmentos sociais com larga influência política.

O processo decisório efetivo não só se manteve restrito aos atores institucionais (governos, partidos, burocracias das agências estatais de planejamento etc.) como foi permeável à influência de grupos econômicos e políticos. Esse autêntico bloqueio à agenda da reforma urbana congrega as ideias do empresariamento e reflete a "ambiguidade constitutiva" do modelo de desenvolvimento urbano brasileiro, no qual as fronteiras entre público e privado e entre legal e ilegal são tênues. Ademais, "na área do desenvolvimento urbano, os processos decisórios se dão no interior da burocracia de gestão do território, altamente permeada por redes de influência que articulam setores empresariais, mandatos parlamentares e partidos políticos", pois não se pode ignorar que "empreiteiras de obras públicas, concessionários de serviços e incorporadoras e construtoras são os maiores financiadores de campanhas eleitorais locais" (Rolnik, 2009:38).

Também (e sobretudo) por isso, a concepção e implantação dos Planos Diretores se manteve apartada da gestão orçamentária - lugar onde, de facto, podem ser identificadas e constatadas as prioridades efetivas de um governo - , ainda que nas três cidades tenha sido observada a obrigatoriedade litúrgica de audiências públicas sobre o Plano Plurianual de Investimentos (PPA), a Lei de Diretrizes Orçamentárias (LDO) e a Lei Orçamentária Anual (LOA).

A hipótese explicativa é que as ações de empresariamento não só ofuscam os foros participativos institucionalizados, tornando-os burocráticos e litúrgicos, como na prática concentram as principais decisões relativas ao planejamento e ao desenvolvimento urbano, imprimindo um compasso político amplamente favorável aos interesses empresariais que compromete os enunciados da função social da cidade e de processos decisórios participativos inscritos no marco legal da política urbana brasileira. Portanto, a distância entre o normativo e o fático é abissal. 
Quadro 1

\section{Resumo comparativo dos Planos Diretores Participativos}

\begin{tabular}{|c|c|c|c|}
\hline Variável/Cidade & Piracicaba & Bauru & Rio Claro \\
\hline Período & $2003-06$ & $2005-08$ & $2005-07$ \\
\hline Governo & $\begin{array}{c}\text { PT (2001-04) } \\
\text { PSDB (2005-12) }\end{array}$ & $\begin{array}{c}\text { PDT (2005-08) } \\
\text { PMDB (2009-12) }\end{array}$ & $\begin{array}{c}\text { PFL (2005-08) } \\
\text { PMDB (2009-12) }\end{array}$ \\
\hline Organização societária & $\begin{array}{c}\text { Média: associações } \\
\text { comunitárias e entidades de } \\
\text { classe }\end{array}$ & $\begin{array}{l}\text { Forte: associações comunitárias } \\
\quad \text { e entidades de classe }\end{array}$ & Fraca: entidades de classe \\
\hline $\begin{array}{l}\text { Instrumentos/ } \\
\text { conteúdo }\end{array}$ & $\begin{array}{l}\text { Macrozoneamento, Zonas } \\
\text { Especiais de Interesse Social } \\
\text { (Zeis), Outorga Onerosa, } \\
\text { Imposto Predial e Territorial } \\
\text { Urbano (IPTU) Progressivo, } \\
\text { Direito de Preempção e Estudo } \\
\text { de Impacto de Vizinhança, } \\
\text { Transferência do Direito de } \\
\text { Construir etc. }\end{array}$ & $\begin{array}{c}\text { Macrozoneamento, Zonas } \\
\text { Especiais de Interesse Social } \\
\text { (Zeis), Outorga Onerosa, } \\
\text { Imposto Predial e Territorial } \\
\text { Urbano (IPTU) Progressivo, } \\
\text { Direito de Preempção e Estudo } \\
\text { de Impacto de Vizinhança, } \\
\text { Transferência do Direito de } \\
\text { Construir etc. }\end{array}$ & $\begin{array}{l}\text { IPTU progressivo, Direito de } \\
\text { Preempção, Zeis, Estudo de } \\
\text { Impacto de Vizinhança etc. } \\
\text { Obs.: não foram } \\
\text { incorporados a Outorga } \\
\text { Onerosa e o Consórcio } \\
\text { Imobiliário }\end{array}$ \\
\hline $\begin{array}{l}\text { Instrumentos } \\
\text { regulamentados }\end{array}$ & Zeis e EIV & Zeis & Nenhum \\
\hline Legislação & Lei no 186, de 10/10/2006 & Lei no 5.631 , de 22/8/2008 & $\begin{array}{c}\text { Lei no 3.806, de } \\
\text { 28/12/2007 } \\
\text { (atualmente em revisão) }\end{array}$ \\
\hline Formatos participativos & $\begin{array}{c}\text { Conselho da Cidade, } \\
\text { audiências públicas, } \\
\text { conferências, iniciativa popular } \\
\text { legislativa etc. }\end{array}$ & $\begin{array}{c}\text { Conselho do Município, } \\
\text { audiências públicas, } \\
\text { conferências, iniciativa popular } \\
\text { legislativa etc. }\end{array}$ & $\begin{array}{c}\text { Conselho de } \\
\text { Desenvolvimento Urbano, } \\
\text { audiências públicas, } \\
\text { conferências }\end{array}$ \\
\hline $\begin{array}{l}\text { Participação posterior } \\
\text { ao Plano Diretor }\end{array}$ & $\begin{array}{c}\text { Conselho da Cidade } \\
\text { (institucionalizado), } \\
\text { conferências, audiências } \\
\text { públicas }\end{array}$ & $\begin{array}{l}\text { Conselho do Município } \\
\text { (implantado em 2013), } \\
\text { conferências, audiências públicas }\end{array}$ & $\begin{array}{c}\text { Conselho de } \\
\text { Desenvolvimento Urbano, } \\
\text { audiências públicas na } \\
\text { revisão }\end{array}$ \\
\hline
\end{tabular}

Fonte: Elaboração pelos autores.

\section{Conclusões}

Três referências analíticas merecem registro. No plano econômico, destaca-se o fato de os municípios analisados exercerem capacidade de polarização regional, ainda que suas configurações sejam distintas: enquanto Piracicaba e Rio Claro mantêm importantes estruturas 
industriais, Bauru se destaca pela pujança do setor terciário (Goulart, Terci e Otero, 2013). Na dimensão urbanística, são cidades médias que, embora reproduzam o modelo de espoliação urbana característico da produção do espaço urbano no Brasil, ampliaram significativamente a oferta de infraestrutura nas últimas décadas, o que representou saltos expressivos em diversos indicadores sociais que antecederam os Planos analisados. Por fim, verifica-se uma importante mudança de orientação política dos gestores públicos motivada pelo cenário econômico de escassez de investimentos, a qual se traduziu na transição de uma postura de gerenciamento para outra de empresariamento das cidades.

Em todos os três casos, a participação nos processos de formulação de novos Planos Diretores transcorreu mediante mecanismos de representação: escolha de delegados, transferência decisória (independente de seu alcance), participação em foros institucionais e conselhos. O período analisado (2001-11) compreende um contexto de implantação do avançado marco regulatório da política urbana e de recuperação econômica do país (Rolnik e Klink, 2011), que permitiu a adoção de políticas desenvolvimentistas que também se refletiram nas cidades médias. No âmbito do desenvolvimento urbano, cabe lembrar os impactos de ações como o Programa de Aceleração do Crescimento (PAC) e o Programa Minha Casa Minha Vida (PMCMV). Assim conviveram, de um lado, a obrigação legal de fazer Planos Diretores com base nos princípios e instrumentos do Estatuto da Cidade e, de outro, a pressão para que os municípios atraíssem investimentos e fossem proativos, enfim, que replicassem o modelo do empresariamento.

No computo geral, os dados disponíveis e o exame empírico revelam que o caráter participativo na elaboração dos Planos Diretores transcorreu com largo controle exercido pelos atores estatais, cenário que se manteve no período subsequente, mesmo quando existiram formalmente espaços compartilhados como os conselhos municipais de política urbana de múltiplas denominações. Tal movimento se inscreve no quadro mais geral da democratização brasileira, no qual

a sociedade civil teve sua institucionalidade criada por dois processos, a reação dos setores populares ao processo antidemocrático de modernização do país que interferiu intensamente na sua vida cotidiana e um processo de democratização que fez das associações civis atores importantes no processo de aprofundamento democrático. [Avritzer, 2012:394]

Tal vigor, se não arrefeceu, foi insuficiente para influir mais ativamente na regulação urbanística.

Não obstante o elevado índice de municípios brasileiros que fizeram ou revisaram seus Planos Diretores no período contemporâneo (quase 90\%), há fortes evidências de que o novo marco institucional da política urbana no Brasil ainda padece de efetividade tanto no que se refere à regulamentação e implantação dos instrumentos urbanísticos do Estatuto da Cidade quanto à democratização dos processos de tomada de decisões sobre políticas públicas de gestão urbana (Santos Jr. e Montandon, 2011).

Em que pesem as limitações apontadas, o Estatuto da Cidade segue como referência institucional inovadora para promover a reforma urbana; contudo, as fórmulas participativas 
adotadas nos Planos Diretores analisados se revelaram frágeis, constatação inseparável da própria fraqueza das organizações societárias e, sobretudo, da alta dependência do sistema político e da primazia institucional do Executivo no processo decisório. Nesse sentido, a análise de Villaça (2004) propositalmente lembrada na epígrafe soa profética: a encruzilhada atual dos Planos Diretores continua opondo interesses de minorias (identificados no empresariamento) aos da maioria da população (sintetizados no Estatuto da Cidade), cuja resolução, longe de se limitar às tecnicalidades do planejamento urbano e do marco institucional, é de natureza política.

\section{Referências}

ALMEIDA, Maria Hermínia T.; CARNEIRO, Leandro P. Liderança local, democracia e políticas públicas no Brasil. Opinião Pública, v. 9, n. 1, p. 124-147, 2003.

ARANTES, Otília; VAINER, Carlos; MARICATO, Ermínia. A cidade do pensamento único: desmanchando consensos. Petrópolis: Vozes, 2000.

ARAUJO, Cicero. O processo constituinte: sociedade civil e povo na transição. In: GOULART, Jefferson O. (Org.). As múltiplas faces da Constituição cidadã. São Paulo: Cultura Acadêmica, 2009. p. 13-25.

ARRETCHE, Marta. Continuidades e descontinuidades da federação brasileira: de como 1988 facilitou 1995. Dados — Revista de Ciências Sociais, v. 52, n. 2, p. 377-423, 2009.

AVRITZER, Leonardo. Instituições participativas e desenho institucional: algumas considerações sobre a variação da participação no Brasil democrático. Opinião Pública, v. 14, n. 1, p. 43-64, 2008.

AVRITZER, Leonardo. Sociedade civil e Estado no Brasil: da autonomia à interdependência política. Opinião Pública, v. 18, n. 2, p. 383-398, 2012.

BRUGUÉ, Quim; VALLÈS, Josep Maria. New-style councils, new-style councillors: from local government to local governance. Governance: An International Journal of Policy, Administration, And Institutions, v.18, n. 2, p. 197-226, 2005.

BUVINICH, Danitza P. R. O mapeamento da institucionalização dos conselhos gestores de políticas públicas nos municípios brasileiros. Rev. Adm. Pública, v. 48, n. 1, p. 55-82, 2014.

CANO, Wilson (Org.). A interiorização do desenvolvimento econômico no Estado de São Paulo. São Paulo: Seade, 1988. (Coleção Economia Paulista, v.1, n. 1).

CARVALHO, Caroline C. O Plano Diretor e a dinâmica de construção do espaço urbano: o caso de Bauru - um estudo a partir das Zonas Especiais de Interesse Social. Relatório Final de Pesquisa de Iniciação Científica apresentado à Fapesp. Bauru: Faac/Unesp, 2013.

CASTELLS, Manuel; BORJA, Jordi. As cidades como atores políticos. Novos Estudos, n. 45, p. $152-$ 166, 1996.

ESTATUTO DA CIDADE. Guia para implementação pelos municípios e cidadãos: Lei oㅜ 10.257, de 10/7/2001, que estabelece diretrizes gerais da política urbana. 2. ed. Brasília: Câmara dos Deputados, Coordenação de Publicações, 2002. 
FADUL, Élvia et al. A administração pública no Brasil: reflexões sobre o campo de saber a partir da divisão acadêmica da Associação Nacional de Pós-Graduação e Pesquisa em Administração (20092013). Rev. Adm. Pública, v. 48, n. 5, p. 1329-1354, 2014.

GOULART, Jefferson O. Processo constituinte e arranjo federativo. Lua Nova, n. 88, p. 185-215, 2013.

GOULART, Jefferson O.; TERCI, Eliana T.; OTERO, Estevam V. A dinâmica urbana de cidades médias no interior paulista sob o Estatuto da Cidade. Revista Brasileira de Estudos Urbanos e Regionais, v. 15, n. 1, p. 183-200, 2013.

GURGEL, Claudio; JUSTEN, Agatha. Controle social e políticas públicas: a experiência dos Conselhos gestores. Rev. Adm. Pública, v. 47, n. 2, p. 357-378, 2013.

HARVEY, David. Do gerenciamento ao empresariamento: a transformação da administração urbana no capitalismo tardio. Espaço \& Debates - Revista de Estudos Regionais e Urbanos, v. 1, n. 39, p. 48-63, 1996.

KLEBA, Maria E.; COMERLATTO, Dunia; FROZZA, Kenia. Instrumentos e mecanismos de gestão: contribuições ao processo decisório em conselhos de políticas públicas. Rev. Adm. Pública, v. 49, n. 4, p. 1059-1079, 2015.

LAVALLE, Adrian G.; VERA, Ernesto I. A trama da crítica democrática: da participação à representação e à accountability. Lua Nova, n. 84, p. 95-139, 2011.

LEME, Heládio C. O federalismo na Constituição de 1988: representação política e a distribuição de recursos tributários. Dissertação (mestrado em ciências sociais) — Instituto de Filosofia e Ciências Humanas, Universidade de Campinas, Campinas, 1992.

LINZ, Juan; STEPAN, Alfred. Problems of democratic transitions and consolidation. Southern Europe, South America, and post-communist Europe. Baltimore; Londres: The Johns Hopkins University Press, 1996.

LÓPEZ, Gabriela R. O processo participativo do Plano Diretor de Bauru. Relatório Final de Pesquisa de Iniciação Científica apresentado à Fapesp. Bauru: Faac/Unesp, 2013.

MARICATO, Ermínia T. O impasse da política urbana no Brasil. Petrópolis: Vozes, 2011.

O’DONNELL, Guillermo. Poliarquias e a (in)efetividade da lei na América Latina. Novos Estudos, n. 51, p. 37-61, 1998.

OLIVEIRA, Fabricio. Crise, reforma e desordem do sistema tributário nacional. Campinas: Ed. Unicamp, 1995.

QUEIROZ, Leonardo L. Entrevista: reflexões de um reformador contemporâneo do Estado brasileiro: entrevista com Luiz Carlos Bresser-Pereira. Rev. Adm. Pública, v. 48, n. 4, p. 1051-1070, 2014.

RIBEIRÃO, Carina. O Plano Diretor e a produção imobiliária em Rio Claro — 1980-2010. Relatório de Resultados de Pesquisa de Iniciação Científica, 2012.

RIGITANO, Maria Helena C. Consulta à comunidade: princípios, métodos e avaliação da experiência dos planos diretores do Município de Bauru — SP. Dissertação (mestrado em engenharia urbana) — Universidade Federal de São Carlos, São Carlos, 2008. 
ROLNIK, Raquel. Democracia no fio da navalha — limites e possibilidades para a implementação de uma agenda de reforma urbana no Brasil. Revista Brasileira de Estudos Urbanos e Regionais, v. 11, n. 2, p. 31-50, 2009.

ROLNIK, Raquel; KLINK, Jeroen. Crescimento econômico e desenvolvimento urbano. Novos Estudos, n. 89, p. 89-109, 2011.

SALLUM Jr., Brasilio. Labirintos: dos generais à Nova República. São Paulo: Hucitec, 1996.

SANDISO, Carlos. Governing to deliver: three keys for reinventing Government in Latin America and the Caribbean. Governance: An International Journal of Policy, Administration, And Institutions, v. 28 n. 2, p. 123-126, 2015. Disponível em: <http://onlinelibrary.wiley.com/doi/10.1111/gove.12138/ epdf >. Acesso em: 25 jan. 2016.

SANTOS, Célia R. A gestão da informação na implantação e controle de um planejamento estratégico - Caso "Bauru + 10 - Construindo o Futuro". In: CONGRESSO BRASILEIRO DE CIÊNCIAS DA COMUNICAÇÃO, XXVI, 2003. Disponível em: <www.portcom.intercom.org.br/pdfs/4065311 4249898189292911734646716101243.pdf>. Acesso em: 23 jan. 2013.

SANTOS JR., Orlando A.; MONTANDON, Daniel T. Os Planos Diretores Municipais pós-estatuto da cidade: balanço crítico e perspectivas. Rio de Janeiro: Letra Capital; Observatório das Cidades; Ippur/UFRJ, 2011.

SIQUEIRA, Elisabete S. A gestão de projetos e a produção da cidadania na Associação dos Favelados de Piracicaba. Dissertação (mestrado em administração) — Pontifícia Universidade Católica de São Paulo, São Paulo, 1993.

SOUZA, Celina. Estado da arte da pesquisa em políticas públicas. In: HOCHMAN, Gilberto; ARRETCHE, Marta; MARQUES, Eduardo (Org.). Políticas públicas no Brasil. Rio de Janeiro: Fiocruz, 2007. p. 65-86.

STEPAN, Alfred (Org.). Democratizando o Brasil. Rio de Janeiro: Paz e Terra, 1988.

VILLAÇA, Flávio. Uma contribuição para a história do planejamento urbano no Brasil. In: DEAK, Csaba; SCHIFFER, Sueli R. (Org.). O processo de urbanização do Brasil. São Paulo: Edusp, 2004. p. 169-243.

Jefferson O. Goulart é doutor em ciência política pela Universidade de São Paulo (USP), professor do Departamento de Ciências Humanas da Universidade Estadual Paulista (Unesp) e pesquisador do Centro de Estudos de Cultura Contemporânea (Cedec). E-mail: jgoulart@faac.unesp.br.

Eliana Tadeu Terci é doutora em história pela Universidade de São Paulo (USP) e professora do Departamento de Economia, Administração e Sociologia da Escola Superior de Agricultura Luiz de Queiroz da Universidade de São Paulo (Esalq/USP). E-mail: etterci@usp.br.

Estevam Vanale Otero é doutor em arquitetura e urbanismo pela Universidade de São Paulo (USP) e professor da Faculdade de Engenharia, Arquitetura e Urbanismo da Universidade Metodista de Piracicaba (Unimep). E-mail: estevamotero@yahoo.com. 